\title{
Double Star TC-1 observations of component reconnection at the dayside magnetopause: a preliminary study
}

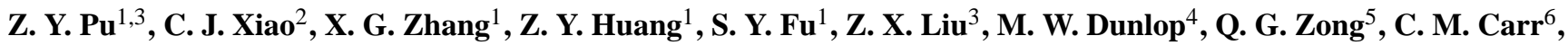 \\ H. Réme ${ }^{7}$, I. Dandouras ${ }^{7}$, A. Fazakerley ${ }^{8}$, T. Phan ${ }^{9}$, T. L. Zhang ${ }^{10}$, H. Zhang ${ }^{1}$, and X. G. Wang ${ }^{11}$ \\ ${ }^{1}$ School of Earth and Space Sciences, Peking University, Beijing 100871, China \\ ${ }^{2}$ National Astronomical Observatories, Chinese Academy of Science, Beijing 100012, China \\ ${ }^{3}$ Center for Space Science and Applied Research, Chinese Academy of Science, Beijing 100080, China \\ ${ }^{4}$ Space Science and Technology Department, Rutherford Appleton Laboratory, Chilton, Oxfordshire, OX11 0QX, UK \\ ${ }^{5}$ Center for Space Physics, Boston University, Boston, Mass 02215, USA \\ ${ }^{6}$ SAPG, The Blackett Laboratory, Imperial College, London SW7 2BZ, UK \\ ${ }^{7}$ Centre d'Etudes Spatiale des Rayonnements, BP 4346, 31028 Toulouse cedex 4, France \\ ${ }^{8}$ Mullard Space Science Laboratory, University College London, Surrey RH5 6NT, UK \\ ${ }^{9}$ Space Science Laboratory, University of California Berkeley, Berkeley CA 94720, USA \\ ${ }^{10}$ Space Research Institute, Austrian Academy of Sciences, OAW, Graz, A-8010, Austria \\ ${ }^{11}$ Center for Plasma Physics, Dalian Univerity of Science and Technology, Dalian 116024, China
}

Received: 14 February 2005 - Revised: 2 August 2005 - Accepted: 19 August 2005 - Published: 8 November 2005

Part of Special Issue "Double Star - First Results"

\begin{abstract}
In spring 2004 Double Star TC-1 measured a number of reconnection signatures at the dayside low-latitude magnetopause (MP) when there was a notable $B_{y}$ component in the magnetosheath. In a number of events we can show that reconnection was operating nearby TC- 1 in the subsolar MP region. In this paper we describe three representative events: (a) event on 21 March 2004 in which the reconnection site can be remotely monitored, the spacecraft was passing by the X-line; (b) event on 12 March 2004 in which TC-1 observed the magnetospheric part of the quadrupolar field, together with a consistent flow reversal; (c) event on 26 March 2004 which occurred for northward IMF, TC- 1 observed a reversal of $v_{y}$ across the equatorial MP. In these events the shear angles across the MP were considerably smaller than $180^{\circ}$; a noticeable guide field was present. These observations are consistent with near equatorial component merging, suggesting that component reconnection preferably occurs at the dayside low-latitude MP. There is evidence that when a pronounced magnetic shear across the MP exists in the $B_{y}$ component, reconnection may operate at the dayside low-latitude MP for northward IMF $B_{z}$.
\end{abstract}

Keywords. Space plasma physics (Magnetic reconnection) - Magnetospheric physics (Magnetopause, cusp, arid boundary layers; Solar wind-magnetosphere interactions)

Correspondence to: $\mathrm{Z} . \mathrm{Y} . \mathrm{Pu}$

(zypu@pku.edu.cn)

\section{Introduction}

Magnetic reconnection at the magnetopause (MP) is the primary mechanism responsible for the transfer of solar wind energy and plasma into the magnetosphere. Previous observations have considerably increased our understanding of this key process in the solar wind-magnetosphere coupling (Paschmann et al., 1979; Sonnerup et al., 1981; Russell and Elphic, 1978; Gosling, 1990).

However, some fundamental questions remain unclear. It is not yet quite known where reconnection first occurs and how the resulting structure moves (Cooling et al., 2001). Whether reconnection can operate at the dayside low-latitude MP for northward IMF $B_{z}$ is also a matter of ongoing discussions. The anti-parallel merging model (Crooker, 1979; Luhmann et al., 1984) suggests that when a non-zero interplanetary magnetic field (IMF) $B_{y}$ is present, MP reconnection takes place preferentially at higher latitudes where magnetospheric and magnetosheath magnetic fields are anti-parallel. On the contrary, the component merging model suggests that reconnection predominately appears in the subsolar region along the X-line which passes through the subsolar point with a tilt depending on the orientation of the IMF (Gonzalez and Mozer, 1974; Cowley, 1976; Sonnerup et al., 1981). SuperDARN HF radar measurements (Chisham et al., 1999) found that the anti-parallel merging hypothesis matched the data far better than the subsolar merging hypothesis. Evidence for anti-parallel reconnection in the cusp region has 
TC-1 observations on 21-03-2004

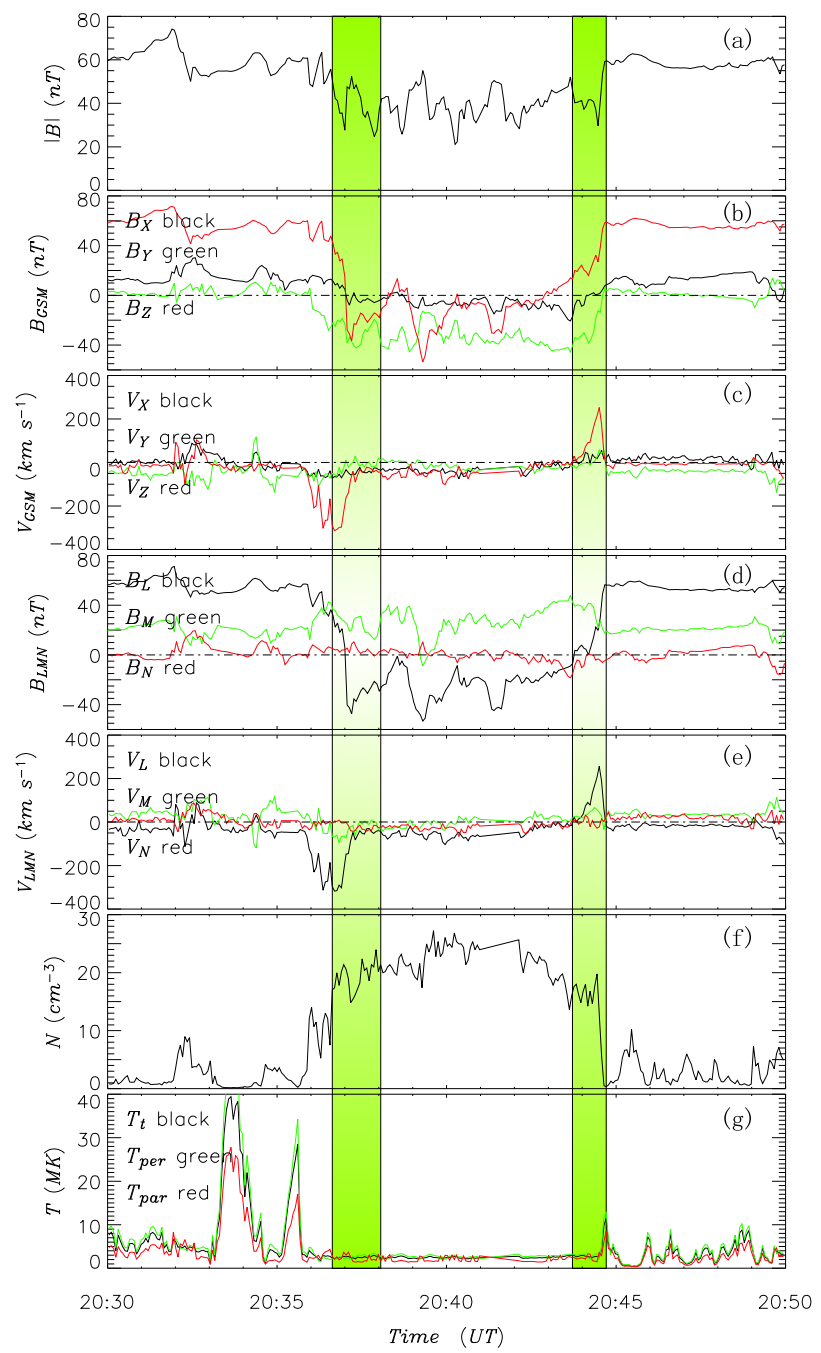

Fig. 1. TC-1 measurements for the two magnetopause crossings on 21 March 2004 (details are shown in the text).

recently been observed by Cluster (Zong et al., 2003). On the other hand, at the low-latitude MP, reconnection signatures have been detected for a large range of IMF orientation (Scurry et al., 1994). ISEE observations of flux transfer events (FTEs) (Russell and Elphic, 1978) when the IMF is not due southward are consistent with near equatorial component merging (Russell et al., 1985). Particle distribution measurements by AMPTE/CCE and Polar spacecraft suggest that for northward IMF, reconnection happens on the tailward side of the cusp (Song and Russell, 1992), as well as equatorward of the cusp on the dayside (Onsager and Fuselier, 1994; Fuselier et al., 1997; Chandler et al., 1999). Nevertheless, direct observations of reconnecting magnetic fields and accelerated plasmas are highly required to verify this suggestion.

The Double Star TC-1 orbit has an apogee of $\sim 12.4 R_{E}$, a perigee of $577 \mathrm{~km}$, an inclination of $28.25^{\circ}$, and an orbital period of 27.4 h (Liu et al., 2005). In spring $2004 \mathrm{TC}-1$ traversed the dayside MP more than sixty times and observed a large number of reconnection signatures when a non-zero IMF $B_{y}$ existed. This paper will study three such examples in some detail.

In this study, we use spin average data which have a 4-s resolution from the Fluxgate Magnetometer (FGM) (Carr et al., 2005), Hot Ion Analyzer (HIA) (Réme et al., 2005) and Plasma Electron and Current Experiment (PEACE) (Fazarkeley et al., 2005).

\section{Observations}

A number of events exist in which ongoing reconnection was not far from TC-1 at the dayside low-latitude MP. This section presents three representative events.

\subsection{Event 21 March 2004}

First we show an event in which the reconnection site can be remotely monitored. Around 20:40 UT on 21 March 2004 , TC-1 was located at $\sim(10.3,-1.4,-2.5) R_{E}(\mathrm{GSM})$. Figure 1 shows, from top to bottom, the total magnetic field (a), the three components of the magnetic field and the thermal ion velocity in the GSM coordinate system (b and c) and in the MP local boundary system ( $\mathrm{d}$ and $\mathrm{e}$ ), thermal ion density (f) and temperature (g). In the local MP coordinates $\boldsymbol{L}, \boldsymbol{M}$ and $\boldsymbol{N}$ represent, respectively, the direction of the maximum, intermediate and minimum variance of the measured magnetic field and positive $\boldsymbol{N}$ is outward (Sonnerup and Schelible, 1998). In reconnection, merging happens in the $\boldsymbol{L}$-component; the $\boldsymbol{M}$ and $\boldsymbol{N}$ indicates the guide field and normal field direction, respectively.

At $\sim 20: 36$ UT TC-1 went out from the magnetosphere to the magnetosheath; at $\sim 20: 44$ it returned back to the magnetosphere. During this time Cluster stayed just sunward of the bow shock and observed a southward $B_{z}$ with a noticeable dawnward $B_{y}$ for the time period of 20:32-20:40 UT (not shown here). During the outbound and inbound MP crossing, TC-1 detected a southward (-z-direction) and northward (+z-direction) jet, respectively. The $v_{z}$ component of the jets reached $\sim 320 \mathrm{~km} / \mathrm{s}$, much higher than the background magnetosheath flow. It is of interest to note that in the MP current layer $B_{N}$, the magnetic field component normal to the local MP has a weak nonzero value that was positive (negative) for the southward (northward) jet. Therefore, according to the classical reconnection picture, during the outbound and inbound MP traversals, TC-1 was on the southern and northern sides of the X-line, respectively (Phan et al., 2000). This is consistent with the fact that both $v_{z}$ and $v_{L}$ were directed southward and that in the time interval between the outbound and inbound MP crossing, the z-component of the DeHoffmann-Teller frame velocity $\left(V_{H T}\right)_{z}$ (Khraborv and Sonnerup, 1998) as a whole was also negative (not shown here). Figures $2 \mathrm{a}$ and $\mathrm{b}$ show the Walén scatter plot of $\boldsymbol{v}-\boldsymbol{V}_{\boldsymbol{H} T}$ versus $\boldsymbol{V}_{\boldsymbol{A}}$ (in GSE) for the outbound and inbound 

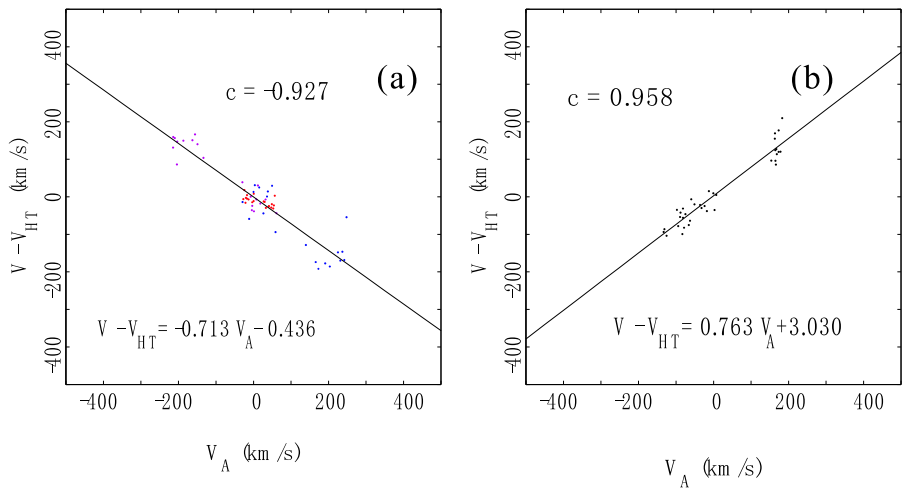

Fig. 2. Walén scatter plot for (a) the outbound MP crossing and (b) the inbound MP crossing on 21 March 2004.

crossing, respectively, where $\boldsymbol{V}_{\boldsymbol{A}}$ denotes the corresponding Alfvén velocity, and $\boldsymbol{v}-\boldsymbol{V}_{\boldsymbol{H}} \boldsymbol{T}$ stands for the plasma velocity in the DeHoffmann-Teller (HT) frame (Khraborv and Sonnerup, 1998).

The slopes of the regression lines and the correlation coefficients are not far from unit, intimating a good Alfvénic nature of the boundary flows of the MP reconnection (Sonnerup, 1995). The slope signs are in agreement with the signs of $B_{N}$, i.e. a negative slope matches $B_{N}>0$ and a positive slope corresponds to $B_{N}<0$ (Sonnerup et al., 1995; Phan et al., 2004).

\subsection{Event 12 March 2004}

Secondly, we show an event on 12 March 2004 in which TC1 observed the quadrupolar field in/near the diffusion region. During this event the TC-1 GSM coordinates were $\sim(10.6$, $-0.4,-1.8) R_{E}$. Geotail was situated at $\sim(-9.9,-22.8$, 9.8) $R_{E}$ (GSM) and observed a southward IMF with nonzero $B_{y}$ for the period of interest. Figure 3 plots the same variables as in Fig. 1. At $\sim 17: 33: 12$ UT the MP suddenly moved inwards, and returned back at $\sim 17: 34: 48$. At these two time instances, TC- 1 observed a pair of opposite jets in the MP boundary layer of which the $v_{L}$ component reached $\sim \mp 250 \mathrm{~km} / \mathrm{s}$. As in Fig. 1 positive $v_{L}$ indicates a northward flow and positive $B_{N}$ denotes an outward magnetic field. The spacecraft thus stayed northward and southward of the X-line at these two instances, respectively. Of interest is the fact that the reversal of $v_{L}$ coincided exactly with the reversal of $B_{N}$. Notice also that variations of $B_{L}, B_{M}$ (relative to the averaged background value), $B_{N}$ and $v_{L}$ between 17:33:15 and 17:35:10 UT are consistent with the prediction of the Hall effect in the ion inertial region (Sonnerup, 1979). The quadrupolar fields in/near the diffusion region have already been observed at the MP (Mozer et al., 2002; Deng and Matsumoto, 2001), as well as in the magnetotail (Nagai et al., 2001; Øieroset et al., 2001). In this event TC-1 was passing by the diffusion region and observed the magnetospheric half of the quadrupolar field, together with a consistent rapid reversal of $v_{L}$. The yellow and gray shadow in Fig. 3 represents, respectively, the area southward and northward of the

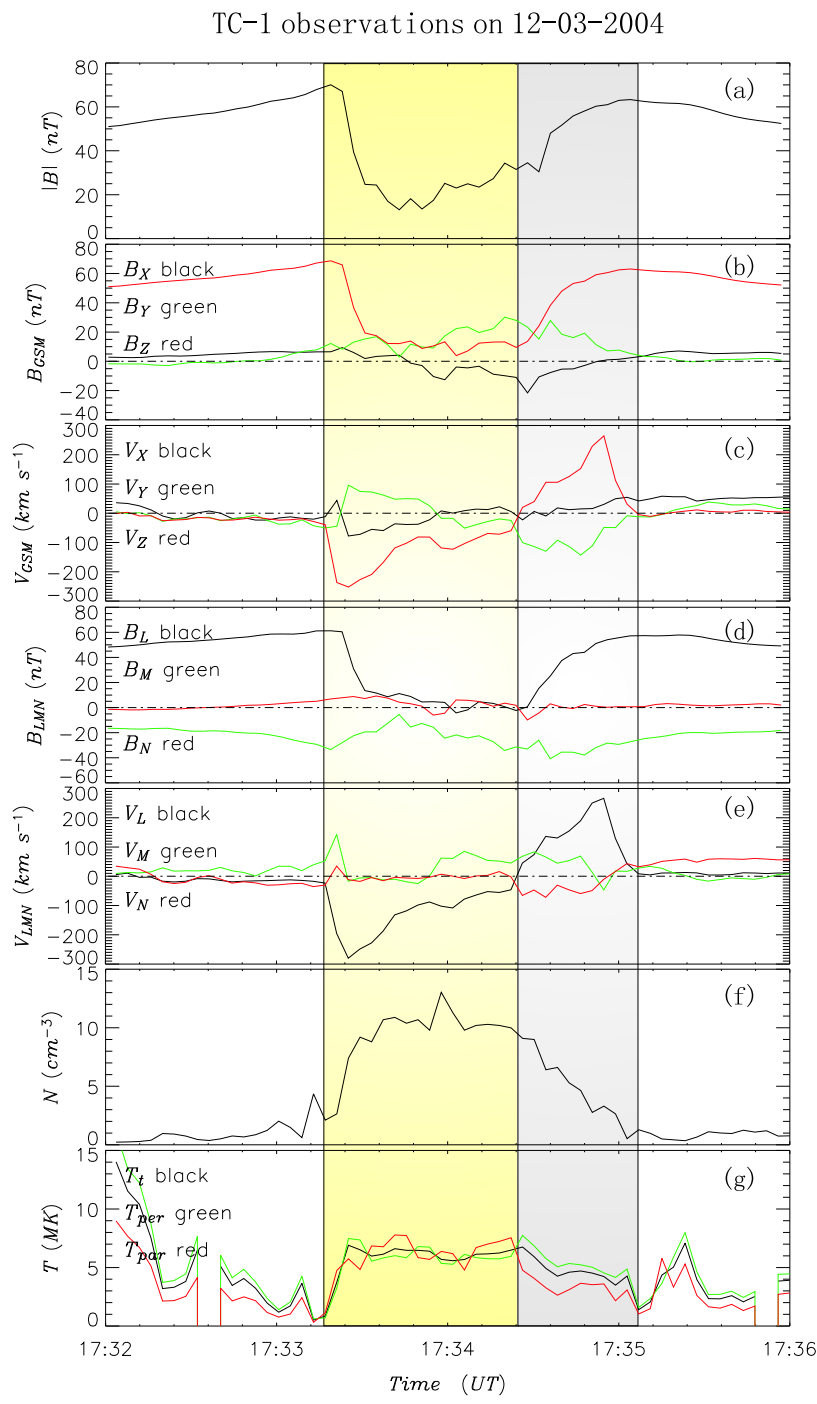

Fig. 3. TC-1 measurement during a brief encounter of the magnetopause on 12 March 2004 (details are in the text). 
TC-1 observations on $26-03-2004$

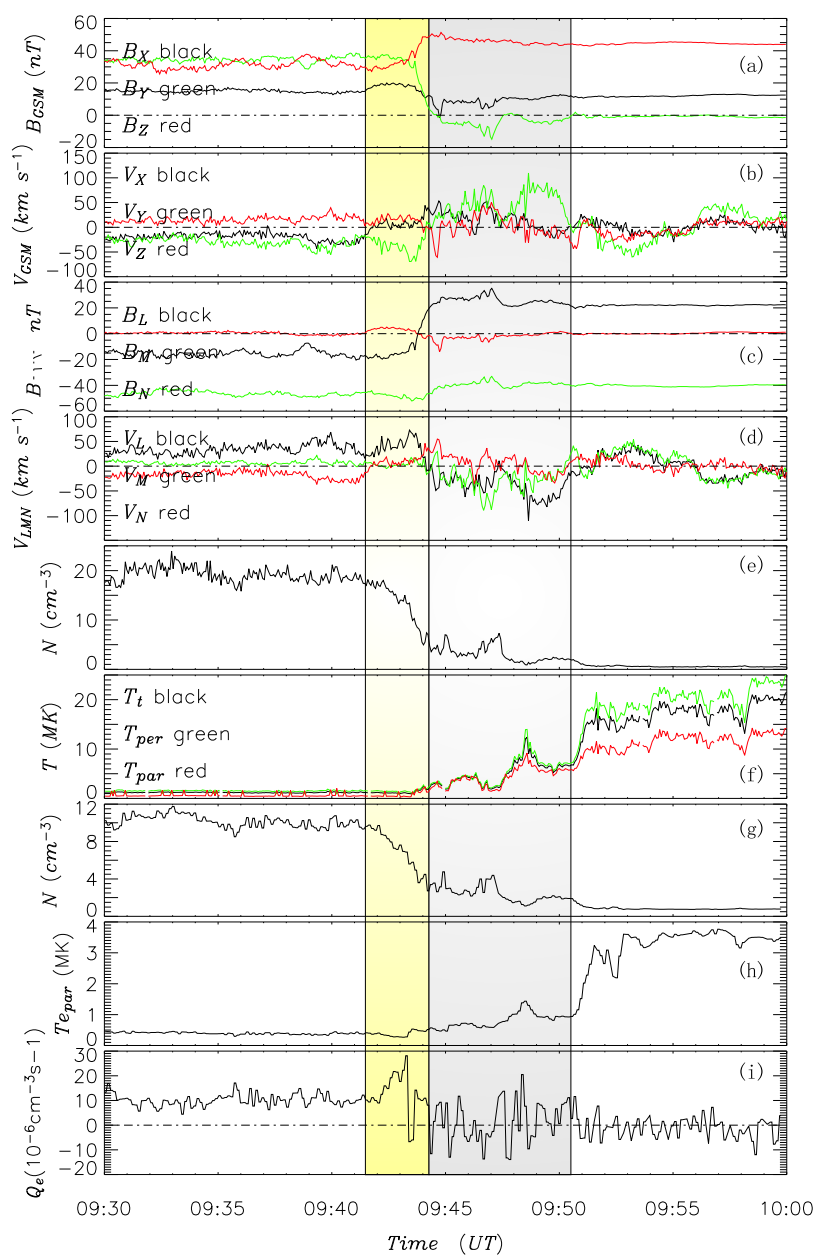

Fig. 4. TC-1 measurements during the inbound crossing of the magnetopause on 26 March 2004 (details are in the text).

$\mathrm{X}$-line. The $\mathrm{X}$-line in the center of the diffusion region was thus not far from the TC-1 position. Note that at the reversals of $B_{N}$ and $v_{L}$, the background guide field $B_{M}$ was $\approx-28 \mathrm{nT}$.

\subsection{Event 26 March 2004}

The third event was a low magnetic shear event observed around $\sim 09: 40: 24$ UT on 26 March 2004 when TC-1 GSM coordinates were $\sim(10.4,-2.2,-1.4) R_{E}$. During this event, Cluster was located in the solar wind just sunward of the bow shock. The Cluster measurement showed that the IMF had a northward orientation with a positive $B_{y}$. In the time period of interest, IMF $B_{z}$ and $B_{y}$ were $6 \mathrm{nT}$ and $9 \mathrm{nT}$, respectively.

Figure 4 displays the measurements of variables similar to those in Fig. 1. In addition, the bottom three panels show the electron density $(\mathrm{g})$, temperature $(\mathrm{h})$ and heat flux parallel to the magnetic field (i) measured by TC-1 PEACE. It is seen that while traversing from the magnetosheath into the magnetosphere, $B_{z}$ increased from $30 \mathrm{nT}$ to $50 \mathrm{nT}$ and $B_{y}$ dropped from $40 \mathrm{nT}$ to $-5 \mathrm{nT}$. In the meantime, TC- 1 encountered a high speed dawnward flow inside the magnetospheric low-latitude boundary layer (LLBL). The LLBL is shaded in gray in Fig. 4. In the adjacent magnetosheath (shaded in yellow) there was an accelerated duskward flow resulting from the draping of magnetosheath field lines (Phan and Paschmann, 1995). The appearance of the $v_{y}$ reversal was accomplished by a nearby reconnection associated with a pronounced local magnetic shear in the y-direction (Gosling et al., 1990).

Figures $5 \mathrm{a}$ and $\mathrm{b}$ show the Walén test plots for the MP crossing on 26 March 2004 when TC- 1 was just on the magnetosheath side and magnetospheric side, respectively. The former has a positive slope, the latter has a negative slope. The magnitudes of the Walén slopes and correlation coefficients were both close to unit, which further supports that TC-1 encountered a merging region while traversing through the MP.

Scurry et al. (1994) reported that low magnetic shear events occur only when the sheath beta is low. By using solar wind and magnetic field parameters measured in the adjacent magnetosheath, we obtain that the magnetosheath beta in this event was $\approx 0.09$, much lower than that in event 21 March $2004(\approx 1.35)$. TC-1 was thus located in the depletion layer in the magnetosheath (Phan and Paschmann, 1995). The magnetic field topology near the merging site will be studied in a future paper.

In short, the reconnection in this event occurred for a northward IMF $B_{z}$ nearby TC-1 at the dayside low-latitude MP.

\section{Discussion}

There are several events in the TC-1 reconnection list which are similar to the three described in the previous section. These observations support the component merging hypothesis and provide new evidence for dayside reconnection for northward IMF $B_{z}$ when an IMF $B_{y}$ is present.

\subsection{Component versus anti-parallel reconnection}

The most straightforward way to distinguish component and anti-parallel reconnection is to determine if there is a guide field at/near the reconnection site, or whether the shear angle across its local MP noticeably deviates from $180^{\circ}$. In the 21 March event TC-1 passed nearby the X-line on the magnetosheath side. Figure 1 shows that the magnetospheric field measured before and after the two jets was fairly quiet with $B_{L} \approx 60 \mathrm{nT}$ and $B_{M} \approx 20 \mathrm{nT}$, while between the two jets, the magnetosheath field was fluctuating around the averaged values of $B_{L} \approx-35 \mathrm{nT}$ and $B_{M} \approx+35 \mathrm{nT}$. We then obtain that the averaged shear angle across the MP near the X-line was $\sim 116^{\circ}$. In event 26 March the shear angle across the local MP can be estimated to be $57^{\circ}$ due to the presence of a strong guide field of $\sim-40 \mathrm{nT}$ (see $B_{M}$ component in Fig. 4). In addition, a $v_{y}$ reversal from being dawnward in the magnetosheath to being duskward in the magnetospheric LLBL was observed. As Gosling et al. (1990) pointed out, such a flow 

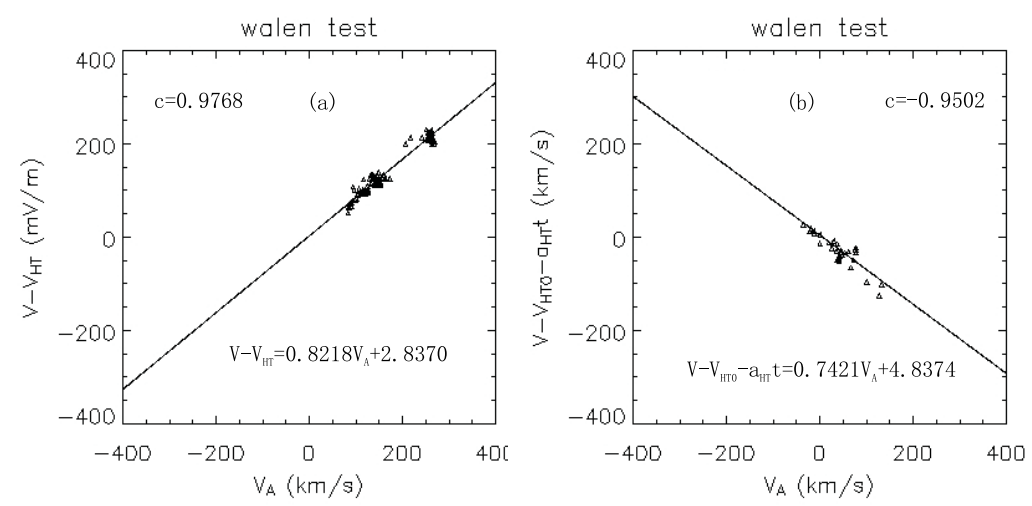

Fig. 5. Walén scatter plot for magnetopause crossing on 26 March 2004, (a) on the magnetosheath side and (b) on the magnetospheric side.

reversal at the MP for strong IMF $B_{y}$ can only be accomplished by a low-latitude component reconnection. There are several other events not presented here which possess the analogous features to the above two events. These observations are apparently consistent with the near equatorial component merging model.

In event 12 March, TC- 1 observed a rapid reversal of $v_{L}$, together with the magnetospheric part of the quadrupolar field caused by the Hall current in/near the ion inertial region. The reconnection site at the MP current sheet was not far from the TC-1 position. As Fig. 3 shows, right at the reversal of $v_{L}$ and $B_{N}$, a non-zero background $B_{M}(\sim-28 \mathrm{nT})$ existed. In the present paper we consider this as a guide field and regard the 12 March event as evidence for component merging. A similar structure has recently been observed in the high-latitude MP boundary (Zong et al., 2005). Further studies of this type of events are highly required.

In a statistical study of accelerated flow events measured by ISSE 2 spacecraft, Scurry et al. (1994) found that merging occurs in the subsolar region for a wide range of magnetic shear angle across the MP. The anti-parallel merging hypothesis cannot completely explain the dayside merging pattern. The TC- 1 observations provide further evidence that when a nonzero IMF $B_{y}$ exists, component reconnection occurs at the dayside low-latitude MP.

\subsection{Dayside reconnection for northward IMF $B_{z}$}

Reconnection occurring tailward of the cusp when the IMF is directed northward has been observed and expected to form the dayside low-latitude boundary layer and proton aurora (Song and Russell, 1992; Phan et al., 2003). By studying the ion and electron data within the dayside LLBL, some authors have shown that component reconnection also occurs equatorward of the cusp for northward IMF (Onsager and Fuselier, 1994; Fuselier et al., 1997; Chandler et al., 1999). We have found evidence (event 26 March 2004) that reconnection can occur for a northward IMF $B_{z}$ at the dayside low-latitude MP. Both reconnecting magnetic field geometry and the reversal of accelerated flow were clearly seen.
There are a few other similar events in the TC-1 list. These observations provide significant new evidence that reconnection may also take place at the low-latitude dayside magnetopause MP for northward IMF. As Fig. 4 indicates this happened when pronounced magnetic shear across the MP existed in the y-direction, which affords further evidence consistent with dayside low-latitude component merging. Nevertheless, the fast flows were slower in northward cases than in the southward IMF merging cases, in general; the bends in the reconnected field lines were less strong, too. The 3-D pattern of reconnected field lines and global consequence of energy and plasma transfer desire further studies.

\section{Summary}

In a certain number of reconnection events observed by TC1 , reconnection was operating nearby the spacecraft in the subsolar MP region. Three representative events were presented in this paper:

(a) 21 March 2004: for southward IMF, the reconnection site can be remotely monitored, as the spacecraft did not cross the X-line; however, the basic feature of the reconnection region can clearly be discerned;

(b) 12 March 2004: for southward IMF, TC-1 observed the magnetospheric part of the quadrupolar field, together with a consistent flow reversal;

(c) 26 March 2004: for northward IMF, TC-1 observed a reversal of $v_{y}$ across the equatorial MP.

In these events the shear angles across the MP were considerably smaller than $180^{\circ}$; a noticeable guide field was present. These observations are consistent with near equatorial component merging, suggesting that component reconnection can occur at the dayside low-latitude MP. There is also evidence that when a pronounced magnetic shear across the MP exists in the $B_{y}$ component, reconnection may operate at the dayside low-latitude MP for northward IMF $B_{z}$. 
Acknowledgements. We thank the Chinese Double Star Data Center for providing data for this study. This work is supported by the CNSF Grant 40390152, Chinese Fundamental Research Project G200000784, and the Key Subject Program in Beijing.

Topical Editor T. Pulkkinen thanks two referees for their help in evaluating this paper.

\section{References}

Carr, C., Brown, P., Zhang, T. L., Gloag, J., Horbury, T., Lucek, E., Magnes, W., O’Brien, H., Oddy, T., Auster, U., Austin, P., Aydogar, O., Balogh, A., Baumjohann, W., Beek, T., Eichelberger, H., Fornacon, K.-H., Georgescu, E., Glassmeier, K.-H., Ludlam, Nakamura, M., and Richter, I.: The Double Star magnetic field investigation: instrument design, performance and highlights of the first year's observations, Ann. Geophys., 23, 2713-2732, 2005.

Chandler, M. O., Fuselier, S. A., Lockwood, M., and Moore, T. E.: Evidence of component merjing equatorward of the cusp, J. Geophys. Res., 104, 22, 623-622, 633, 1999.

Chisham, G., Pinnock, M., Rodger, A. S., Coleman, I. J., Thorolfsson, A., and Cerisier, J. C.: High-time resolution SuperDARN radar observations of the dayside convection response to changes in IM, Astronomy \& Geophysics, 40, 331-333, 1999.

Cooling, B. M. A., Owen, C. J., and Schwartz, S. J.:Role of the magnet osheath flow in determining the motion of open flux tubes, J. Geophys. Res., 106, 18 763-18 775, 2001.

Cowley, S. W. H: Comments on the merging of nonantiparallel magnetic fields, J. Geophys. Res. 81, 3455-3458, 1976.

Crooker, N. U.: Dayside merging and cusp geometry, J. Geophys.Res., 84, 951-959, 1979.

Deng, X. H. and Matsumoto, H.: Rapid magnetic reconnection in the Earth's magnetosphere mediated by whistler waves, Nature, 410, 557-560, 2001.

Fazakerley, A. N., Carter, P. J., Watson, G., Spencer, A., Sun, Y. Q., Coker, J., Coker, P., Kataria, D. O., Fontaine, D., Liu, Z. X., Gilbert, L., He, L., Lahiff, A. D., Mihaljčić, B., Szita, A., Taylor, M. G. G. T., Wilson, R. J., Dedleu, M., and Schwartz, S. J.: The Double Star Plasma Electron and Current Experiment, Ann. Geophys., 23, 2733-2756, 2005.

Fuselier, S. A., Anderson, B. J., and Onsager, T. G.: Electron and ion signatures of field line topolofy at the low-shear magnetopause, J. Geophys. Res., 102, 4847-4863, 1997.

Gonzalez, W. D. and Mozer, F. .: A quantitative model for the potential resulting from reconnection with an arbitrary interplantray magnetic field, J. geophys. Res., 79, 4186-4196, 1974.

Gosling, J. T., Thomsen, M. F., Bame, S. J., and Elphic, R. C.: Plasma flow reversals at the dayside magnetopause and the origin of asymmetric polar cap convection, J. Geophys. Res., 95, 80738084, 1990.

Khrabrov, A. V. and Sonnerup, B. U. Ö.: DeHofmann-Teller Analysis, Analysis Methods for Multi-Spacecraft Data, edited by: Paschmann G. and Daly, P. W., ISSI Science Report, SR-001, 221-248, 1998

Liu, X. L., Escoubet, C. P., Pu, Z. Y., Laakso, H., Shi, J. K., Shen, C., and Hapgood, H.: The Double Star mission, Ann. Geophys., 23, 2707-2712, 2005.

Luhmann, J. G., Walker, R. J., Russell, C. T., Crooker, N. U., Spreiter, J. R., and Stahara, S. S: Patterns of potential magnetic field merging sites on the dayside magnetopause, J. Geophys. Res., 89, 1739-1742, 1984.
Mozer, F. S., Bale, S. D., and Phan, T. D.: Evidence of diffusion egions at a subsolar magnetopause crossing, Phys. Rev. Lett., 9, 015002-1-015002-4, 2002.

Nagai, T., Shinohara, I., Fujimoto, M., Hoshino, M., Saito, Y., Machida, S., and Mukai, T.: Geotail observations of the Hall current system: Evidence of magnetic reconnection in the magnetotail, J. Geophys. Res., 106, 25 929-25 949, 2001.

Øieroset M., T. D., Phan, M., Lin, R. P., and Lepping, R. P.: In situ detection of collisionless reconnection in the earth's magnetotail, Nutre, 412, 414-415, 2001.

Onsager, T. G. and Fuselier, S. A.: The location of magnetic reconnection for northward and southward interplanetary magnetic field, Solar Syatem Plasmas in Space and Time, Geophysical Monograph 84, 183-197, 1994.

Paschmann, G., Sonnerup, B. U. Ö., Papamastorakis, I., Sckopke, N., Haerendel, G., Bame, S. J, Asbridge, J. R., Gosling, J. T., Russell, C. T., and Elphic, R. C.: Plasma acceleration at the earth's magnetopause: Evidence for reconnection, Nature, 282, 243-246, 1979.

Phan, T.-D. and Paschmann, G.: The magnetosheath region adjacent to the dayside magnetopause, Physics of the Magnetopause, edited by: Song, P., Sonnerup, B. U Ö., and Thomsen, M. F., AGU Geophys. Monogr. 90, 115C122, AGU, Washington D. C., 1995.

Phan, T. D., Kistler, L. M., Klecker, B., Haerendel, G., Paschmann, G., Sonnerup, B. U. Ö., Baumjohann, W., Bavassano-Cattaneo, M., Carlson, C., DiLellis, A., Fornacon, K.-H., Frank, L., Fujimoto, M., Georgescu, E., Kokubun, S., Moebius, E., Mukai, T., Øieroset, M., et al.: Extended magnetic reconnection at the Earth's magnetopause from detection of bi-directional jets, Nature, 404, 848, 2000.

Phan, T. D., Frey, H. U., Hrey, S., Peticolas, L., Fuselier, S., Carlson, C., Rème, H., Bosqued, J.-M., Balogh, A., Dunlop, M., Kistler L., Mouikis, C., Dandouras, I., Sauvaud, J.-A., Mende, S., McFadden, J., Parks, G., Moebius, E., Klecker, B., Paschmann, G., Fujimoto, M., Petrinec, S., Marcucci, M. F., Korth, A., and Lundin, R.: Simultaneous Cluster and IMAGE observations of cusp reconnection and auroral proton spot for northward IMF, Geophys. Res. Lett., 30, 1509-1603, 2003.

Phan, T. D., Dunlop, M. W., Paschmann, G., Klecker, B., Bosqued, J. M., Rème, H., Balogh, A., Twitty, C., Mozer, F. S., Carlson, C. W., Mouikis, C., and Kistler, L. M.: Cluster observations of continuous reconnection at the magnetopause under steady interplanetary magnetic field conditions, Ann. Geophys., 22, 23552367, 2004,

SRef-ID: 1432-0576/ag/2004-22-2355.

Réme, H., Dandouras, I., Aoustin, C., Bosqued, J. M., Sauvaud, J. A., Vallat, C., Escoubet, P., Cao, J. B., Shi, J., BavassanoCattaneo, M. B., Parks, G. K., Carlson, C. W., Pu, Z. Y., Klecker, B., Moebius, E., Kistler, L., Korth, A., Lundin, R., and the HIA team.: The HIA instrument on board the Tan Ce 1 Double Star near-equatorial spacecraft and its first results, Ann. Geophys., 23, 2757-2774, 2005.

Russell, C. T. and Elphic, R. C.: Initial ISEE magnetometer results: Magnetopause observations, Space Sci. Rev., 22, 681-715, 1978.

Russell, C. T., Berchem, J., and Luhmann, J. G.: On the source region of flux transfer event, Adv. Space Res., 5, 363-368, 1985.

Scurry, L., Russell, C. T., and Gosling, J. T.: A statistical study of accelerated flow events at the dayside magnetopause, J. Geophys. Res., 99, 14 815-14 829, 1994.

Song, P. and Russell, C. T.: Model of the formation of the low latitude boundary for strongly northward interplanetary magnetic 
field, J. Geophys. Res., 97, 1411-1420, 1992.

Sonnerup, B. U. Ö.: Magnetic reconnection rate, J. Geophys. Res., 79, 1546-1549, 1974.

Sonnerup, B. U. Ö.: Magnetic reconnection, Solar System Physics, edited by: Lanzerotti, L. T., Kennel, C. F., and Parker, E. N., Vol. III, North-Holland, New York, 45-108, 1979.

Sonnerup, B. U. Ö., Paschmann, G., Papamastorakis, I., Sckopke, N., Haerendel, G., Bame, S. J., Asbridge, J. R., Gosling, J. T., and Russell, C. T.: Evidence for magnetic field reconnection at the Earth's magnetopause, J. Geophys. Res., 86, 10 049-10 067, 1981.

Sonnerup, B. U. Ö., Paschmann, G., and Phan, T.-D.: Fluid aspects of reconnection at the magnetopause, Physics of the Magnetopause, edited by: Song, P., Sonnerup, B. U. Ö., and Thomsen, M. F., AGU Geophys. Monogr. 90, 167C180, AGU, Washington, D.C., 1995.
Sonnerup B. U. Ö. and Scheible, M.: Minimum Variation Analysis, Analysis Methods for Multi-Spacecraft Data, edited by: Paschmann G. and Daly, P. W., ISSI Science Report, SR-001, 180-220, 1998.

Zong, Q.-G., Fritz, T. A., Daley, P. W., Korth, A., Dunlop, M., and Balogh, A.: Bursty energetic electrons in the cusp region found by Cluster, Planet. Space Sci., 51, 821-830, 2003.

Zong, Q.-G., Fritz, T. A., Spence, H., Zhang, H., Huang, Z. Y., $\mathrm{Pu}$, Z. Y., Glassmeier, K.-H., Korth, A., Daley, P. W., Balogh, A., and Réme, H.: Plasmoid in the high-latitude boundary/cusp region observed by Cluster, Geophys. Res. Lett., 32, L01101, 2005. 